\title{
STABILITY STUDY OF PRAVASTATIN UNDER HYDROLYTIC CONDITIONS ASSESSED BY HPLC
}

\author{
S. BRAIN-ISASI, C. REQUENA, A. ÁLVAREZ-LUEJE* \\ Bioelectrochemistry Laboratory. \\ Chemical and Pharmaceutical Sciences Faculty \\ University of Chile \\ P.O. Box 233 Santiago 1 \\ Fax: 56-7378920 \\ CHILE \\ (Received: December 20, 2007 - Accepted: May 19, 2008)
}

\begin{abstract}
In this work an HPLC stability-indicating method was developed and applied to study the hydrolytic behavior of pravastatin in different pHs and temperatures. From the system suitability test, the selected chromatographic conditions were a C-18 column, acetonitrile-30 mmol L-1 phosphate buffer solution pH 2 (28:72) as mobile phase, $40^{\circ} \mathrm{C}$ temperature column, a flux of $1 \mathrm{~mL} / \mathrm{min}$ and $239 \mathrm{~nm}$ as wavelength detection. The developed method exhibited an adequate repeatability and reproducibility (CV $0.11 \%$ and $0.49 \%$, respectively) and a recovery higher than $98 \%$. Furthermore, the detection and quantitation limits were $3.4 \times 10^{-7} \mathrm{~mol}$ $\mathrm{L}^{-1}$ and $3.7 \times 10^{-6} \mathrm{~mol} \mathrm{~L}^{-1}$. The kinetic degradation of pravastatin fits to a pseudo-first order kinetic. The degradation was $\mathrm{pH}$-dependent: alkaline $\mathrm{pH}<$ acid $\mathrm{pH}$ and the generation of degradation products was dependent of the media tested (one product in alkaline medium and 4 products in acid medium). Activation energy, kinetic rate constants at different temperatures, $\mathrm{t}_{1 / 2}$ and $\mathrm{t}_{90}$ values are also reported.
\end{abstract}

Key Words: HPLC, Stability, Hydrolysis, Pravastatin

\section{INTRODUCTION}

Pravastatin (Fig. 1) is a well-known cholesterol-lowering agent belonging to "statin" class and are now among the most frequently and efficient prescribed drugs used to treat hypercholesterolemia and significantly reduce the morbidity and mortality associated with coronary heart disease ${ }^{1}$. Pravastatin is quickly absorbed, goes through hepatic metabolism to give a $3 \alpha$-hydroxylated isomeric compound that possesses $10-40 \%$ of the activity of the parent compound and furthermore, an isomeric $3 \alpha, 5 \beta, 6 \beta$-trihydroxylated metabolite ${ }^{2}$.

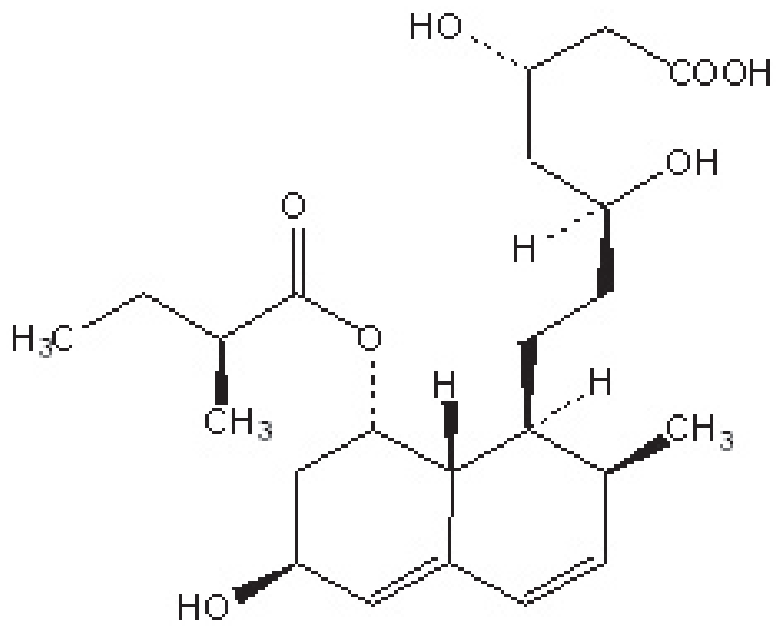

Figure 1. Chemical structure of pravastatin

Pravastatin acts inhibiting the 3-hydroxy-3-methylglutaryl coenzyme A (HMG-CoA) reductase, enzyme that participates in the endogenous cholesterol synthesis. The reductase inhibition is directly related with the structural similitude between the drug and the endogenous substrate, thus both the pharmacological and therapeutic activities of this drug have a close relationship with its structure, which is the basis to development studies about its stability.

The drugs stability investigation represents an important subject in drug quality evaluation. Many environmental conditions such as heat, light or the chemical susceptibility of substances to hydrolysis or oxidation can take part in pharmaceutical stability ${ }^{3,4}$. A testing of drug substance can help to identify the likely degradation products and to give important information on drug's stability. Successively, it can be an essential contribution to the development and validation of stability indicating analytical method used in monitoring of quality of pharmaceutical products. Independent of the final dosage form, forced drug degradation by exposure of drug to different experimental conditions is useful to predict the potential degradation products. Hydrolysis is one of the most common degradation chemical reactions. Since water, either as a solvent or in the form of the potential moisture in the air, contacts most pharmaceutical dosage forms to some degree; the potential for this degradation pathway exist for most drugs and excipients 5 . In recent years, rigorous quality control in the pharmaceutical industries has given rise to a growing need for simple, selective and sensitive analytical methods for the study of the degradation products as well as of the impurities, and thereby to assure the quality of the drug. High performance liquid chromatography is a method with numerous applications for the quantitation of drugs in various matrices-preformulations, dosage forms, and in biological fluids.

Pravastatin has been determined by polarographic pulse polarography ${ }^{6}$ and capillary electrophoresis $(\mathrm{CE})^{7}$ in tablets, and HPLC-UV ${ }^{8-13}$ and HPLCMS $^{14-17}$, HPLC-MS-MS ${ }^{18,19}$, GC-MS ${ }^{20}$ in urine, plasma and other matrix. High throughput methods (HPLC and CE) have been also developed to determine pravastatin in production media ${ }^{21}$. Reviews of analytical methods for the quantitative determination of HMG-CoA reductase inhibitors, including pravastatin, in biological samples and in pharmaceutical formulations have been also published $\mathrm{d}^{22,23}$.

Up to date, no HPLC stability indicating analytical method applied to a systematic study focused on pravastatin degradation have been described in the literature. For this reason, the aim of this paper is to study the hydrolytic behaviour of pravastatin in different $\mathrm{pHs}$ and temperatures and to develop an HPLC analytical method for determination of pravastatin in the presence of its hydrolytic degradation product(s). The novelty of this work is based on the description of a new analytical method, suitable for monitoring the purity of drug substance, and the obtained results can be helpful to assure the quality, safety and effectiveness of pharmacotherapy.

\section{EXPERIMENTAL}

Reagents and drugs. Sodium pravastatin (99.4\% chromatographically pure) was obtained from Gentec, S.A. (Barcelona, Spain). All other reagents employed were analytical or HPLC grade. The water was double distilled and deionised (Milli-Q quality).

Pravastatin stock solution. Pravastatin pure drug was weighted and dissolved in deionised water to obtain a concentration of $1.0 \times 10^{-2} \mathrm{~mol} \mathrm{~L}^{-1}$. This solution was stable for at least one week keeping at $8^{\circ} \mathrm{C}$.

Buffer solutions. $30-\mathrm{mmol} \mathrm{L}^{-1}$ buffer phosphate solution was adjusted at $\mathrm{pH}$ 2 with $30 \%$ phosphoric acid or $30 \% \mathrm{NaOH}$ solutions and employed as mobile phase for HPLC experiments. For the degradation trials, $30-\mathrm{mmol} \mathrm{L}^{-1}$ buffer phosphate solution was adjusted at different $\mathrm{pH}(2-9)$ with $30 \%$ phosphoric acid or $30 \% \mathrm{NaOH}$ solutions.

High Performance Liquid Chromatography (HPLC). HPLC measurements were carried out by using a Waters assembly equipped with a 600 model Controller pump and a 996 model Photodiode Array Detector. The acquisition 
and data treatment were made by means of the Millenium version 2.1 software. As chromatographic column a $\mu$ Bondapak/Porasil C-18 column, $10-\mu \mathrm{m}-$ particle size $(3.9 \mathrm{~mm} \times 150 \mathrm{~mm})$ and as column guards a $\mathrm{C} 18 \mu$ Bondapak (30 $\mathrm{mm} \times 4.6 \mathrm{~mm}$ ) were employed. The injector was a $20 \mu \mathrm{L}$ Rheodyne valve.

Chromatographic conditions. An isocratic elution system composed by acetonitrile-30 mmol L-1 phosphate buffer solution $\mathrm{pH} 2(28: 72)$, at $40^{\circ} \mathrm{C}$ temperature, flow $1 \mathrm{~mL} / \mathrm{min}$ and at a wavelength detection of $239 \mathrm{~nm}$ was employed.

HPLC system suitability test. A $1.0 \times 10^{-4} \mathrm{~mol} \mathrm{~L}^{-1}$ pravastatin solution (30mmol L-1 buffer phosphate solution at $\mathrm{pH}$ 7) was heated at $80^{\circ} \mathrm{C}$ during one hour, with the purpose to obtain both the corresponding peak to pravastatin and its degradation product. This sample was employed to assess the system suitability test. The effects of different concentrations of acetonitrile $(40 \%$, $50 \%, 60 \%, 70 \%$ and $80 \%)$ on the capacity factor $\left(k^{\prime}\right)$, resolution (R), relative retention $(\alpha)$ were tested to determine the best analytical conditions $\mathrm{s}^{24,25}$.

Degradation trials. phosphate buffer solutions $\left(30-\mathrm{mmol} \mathrm{L}^{-1}\right)$ at each selected $\mathrm{pH}(3,5,7,9$ and 12) were spiked with pravastatin to obtain an initial concentration ranging between $1.0 \times 10^{-3} \mathrm{~mol} \mathrm{~L}^{-1}$ and $5.0 \times 10^{-5} \mathrm{~mol} \mathrm{~L}^{-1}$. Solutions were divided in a number of $2 \mathrm{~mL}$ amber vials (at least two for each point of the degradation curve $)$ and then placed in a oven at $80.0,60.0$ and $40^{\circ} \mathrm{C}\left( \pm 0.2^{\circ} \mathrm{C}\right)$. Vials were taken from the oven at selected time intervals depending on both $\mathrm{pH}$ and temperature (each 5-10 min for $\mathrm{pH} \mathrm{3-5}$ and $20-30 \mathrm{~min} \mathrm{pH} \mathrm{7-12}$ at $80^{\circ} \mathrm{C}$ ). Immediately each sample was cooled on ice to quench the reaction and assayed by HPLC. Experiments were carried out in duplicate, and the degradation was monitored over at least three half-lives.

Thin layer chromatography. Preparative TLC experiments were carried out using RP 18 F254 as stationary phase and acetonitrile-water (30:70) as mobile phase. Samples solutions from the alkaline hydrolysis trial $\left(1 \times 10^{-3}\right.$ mol L-1 pravastatin standard solution) were chromatographied and the isolated residue was dissolved in d-DMSO and analyzed by ${ }^{1} \mathrm{H}-\mathrm{NMR}$ and ${ }^{13} \mathrm{C}-\mathrm{NMR}$ (Bruker, Advance DRX 300).

HPLC-ESI-MS. Solutions from the acid hydrolysis trial at $\mathrm{pH} 2\left(1 \times 10^{-4} \mathrm{~mol}\right.$ $\mathrm{L}^{-1}$ pravastatin standard solution) were chromatographied in a HPLC (Agilent 1100 Series) coupled to ESI-MS (Bruker Esquire 4000) using a $\mu$ Bondapak/ Porasil C-18 column, $10-\mu \mathrm{m}$-particle size $(3.9 \mathrm{~mm} \times 150 \mathrm{~mm})$ and an isocratic elution system composed of acetonitrile-1\% formic acid $(30: 70)^{17,22}$.

Activation Energy (Ea). Each Ea value was obtained from Arrehnius model by plotting $\ln k$ vs. $1 / T$ for each concentration tested. The final Ea value represents the average of the Ea calculated for 4 concentrations between $1 \times 10^{-3}$ mol L $\mathrm{L}^{-1}$ and $1 \times 10^{-5} \mathrm{~mol} \mathrm{~L}^{-1}$. In all cases regression coefficients values higher than 0.996 were obtained.

\section{RESULTS AND DISCUSSION}

In order to develop an analytical methodology for pravastatin and its hydrolytic degradation products, different proportions of acetonitrile were assayed. The selection of the optimal working conditions was established through the system suitability assay.

According to the experimental results (Figure 2), while the acetonitrile concentration decrease, the $\mathrm{k}$ ' value diminishes in parallel. Besides, using a $28 \%$ of acetonitrile in the mobile phase, the $\mathrm{R}$ value increases to the highest value. In the same way, the $\alpha$ value peak is gotten using around a $35 \%$ of acetonitrile. In addition, while the mobile phase acetonitrile concentration decreases, the pravastatin and its hydrolytic degradation products chromatographic signals separate in equivalent way. Taking into account the above summarized results, the selected optimal conditions $\left(\mathrm{R}=2.1, \mathrm{k}^{\prime}=5.5, \alpha=1.6\right)$ were: acetonitrile-30 mmol L-1 phosphate buffer solution $\mathrm{pH} 2(28: 72), 40^{\circ} \mathrm{C}$ and $1 \mathrm{~mL} / \mathrm{min}$ flow rate. Under this conditions, pravastatin exhibited a retention time of $8.95 \pm 0.05$ min (Figure 3A) and its corresponding degradation products, retention times of $10.21 \pm 0.087 \mathrm{~min} ; 11.83 \pm 0.064 \mathrm{~min} ; 15.91 \pm 0.39 \mathrm{~min} ; 17.60 \pm 0.17 \mathrm{~min}$ and $19.47 \pm 0.17 \mathrm{~min}$ for hydrolysis at $\mathrm{pH}<7$ (Figure 3B) and only one signal at $1.902 \pm 0.0095 \mathrm{~min}$ for the hydrolysis at $\mathrm{pH}>7$ (Figure $3 \mathrm{C}$ ).

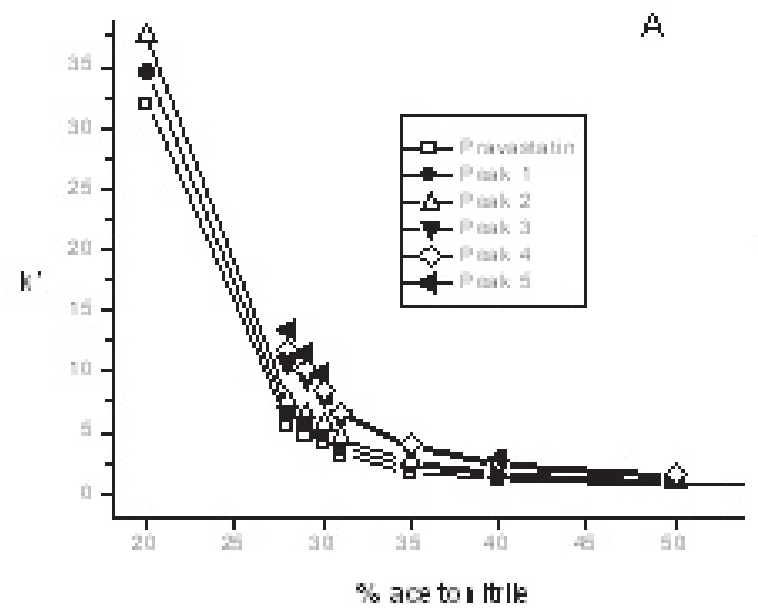

$\mathbf{R}$
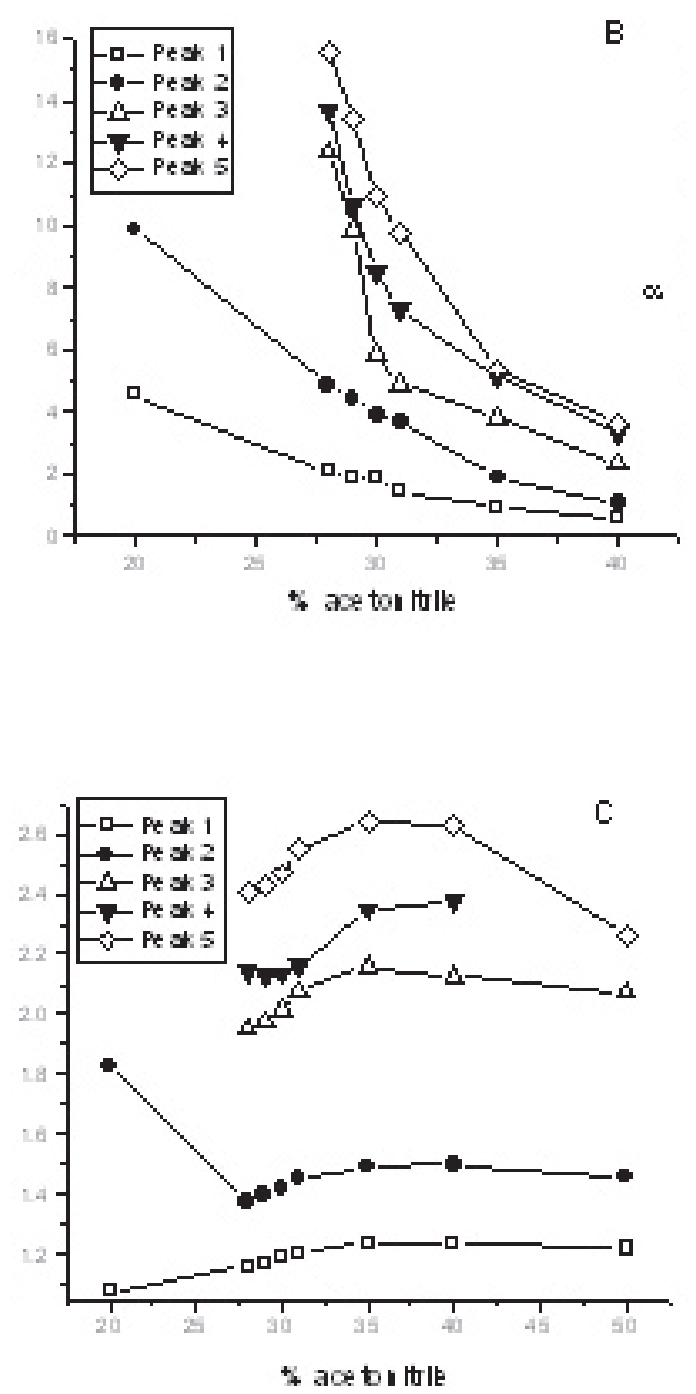

Figure 2. Dependence of percentage acetonitrile on (A) capacity factor: $\left(k^{\prime}\right),(B)$ resolution $(\mathrm{R})$ and $(\mathrm{C})$ relative retention $(\alpha)$ values of pravastatin and it degradation products. All eluents were acetonitrile- $30 \mathrm{mmol} \mathrm{L}^{-1}$ phosphate buffer, pH 2. 

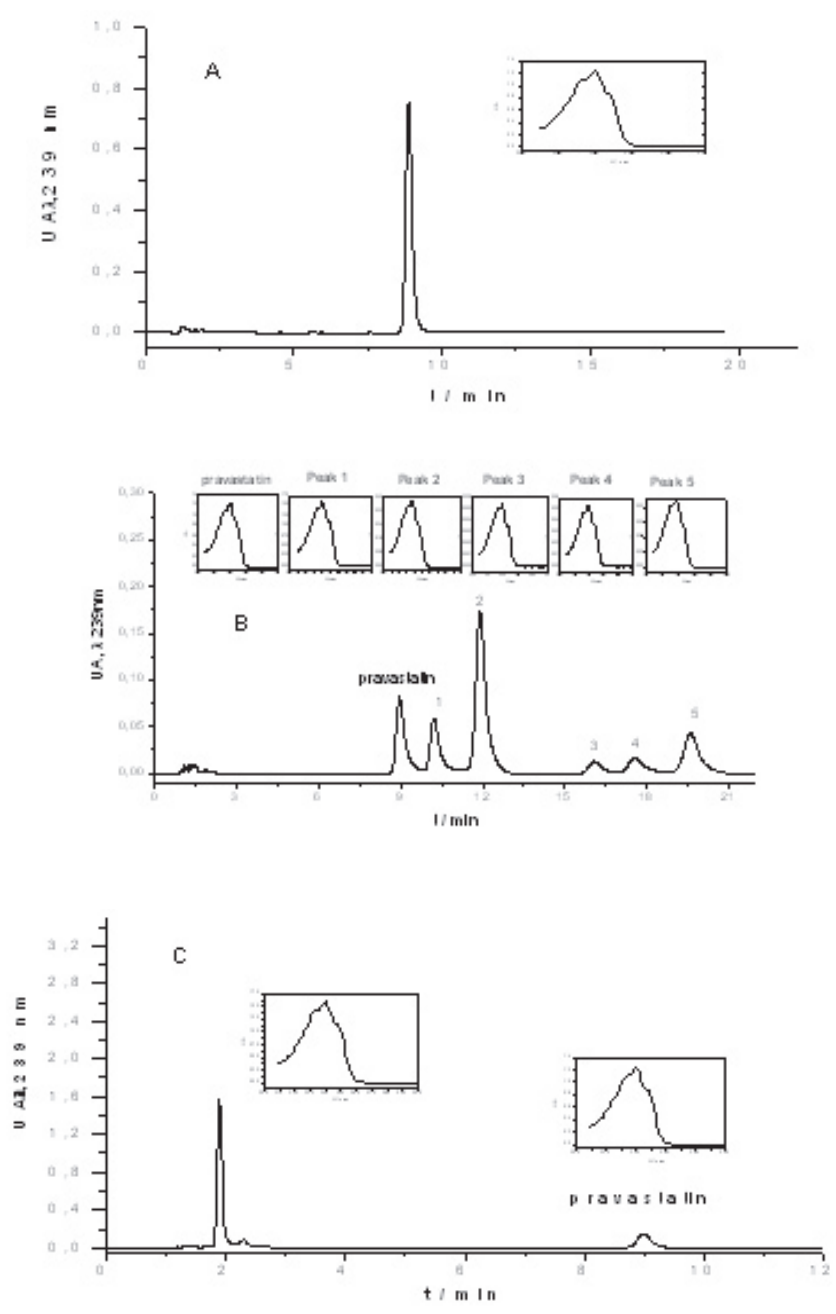

Figure 3. Chromatograms of a $1 \times 10^{-4} \mathrm{~mol} \mathrm{~L}^{-1}$ pravastatin standard solution at $\mathrm{t}=0 \mathrm{~min}(\mathbf{A})$, after $1 \mathrm{~h}$. of hydrolysis at $\mathrm{pH} 3,80^{\circ} \mathrm{C}(\mathbf{B})$ and $6 \mathrm{hrs}$ of hydrolysis at $\mathrm{pH} 12,80^{\circ} \mathrm{C}(\mathbf{C})$ Insert: UV-spectra of each peak.

In Table 1, the analytical evaluation of the new HPLC procedure for pravastatin is summarized. From the obtained analytical parameters we can conclude that the developed chromatographic assay fulfils the analytical requirements, exhibiting an adequate repeatability and reproducibility (CV $0.11 \%$ and $0.49 \%$, respectively) and a recovery higher than $98 \%{ }^{26}$. On the other hand, the concentration range for calibration curves seem to be adequate to follow degradation with detection and quantitation average limits of $3.4 \times 10^{-7} \mathrm{~mol} \mathrm{~L}^{-1}$ and $3.7 \times 10^{-6} \mathrm{~mol} \mathrm{~L}^{-1}$, respectively. The detection (LOD) and quantitation limits (LOQ) of the method, were calculated by using the average $(\mathrm{Yb})$ and standard deviation $(\mathrm{Sb})$ of the blank estimated response, calibration curve slopes $(m)$ and with a signal/noise ratio of 3 and 10 , respectively, according to the following expressions ${ }^{25}$ :

$$
L O Q=\left[\frac{(Y b+10 \cdot S b)}{m}\right] \quad \text { and } \quad L O D=\left[\frac{(Y b+3 \cdot S b)}{m}\right]
$$

Thus, the developed method is sufficiently selective to discriminate pravastatin from its corresponding hydrolytic products, representing a useful tool to follow this type of degradation and to assess pravastatin in the presence of its active metabolite.
Table 1. Analytical parameters for the developed HPLC-UV method.

\begin{tabular}{|l|c|}
\hline Parameter & HPLC-UV $(\lambda=\mathbf{2 3 9} \mathbf{~ n m})$ \\
\hline Repeatability, CV $(\%)^{\mathrm{a}}$ & 0.11 \\
\hline Reproducibility, CV $(\%)^{\mathrm{a}}$ & 0.49 \\
\hline Recovery $(\%)^{\mathrm{b}}$, s.d. & $98.6 \pm 0.9$ \\
\hline Concentration range $\left(\mathrm{mol} \mathrm{L}^{-1}\right)$ & $1 \times 10^{-3}-1 \times 10^{-6}$ \\
\hline Calibration curve & $\mathrm{AUC}=2.74 \times 10^{10}[\mathrm{c}]+72267 \quad(\mathrm{r}=$ \\
& $0.99992 ; \mathrm{n}=7)$ \\
\hline Detection limit $\left(\mathrm{mol} \mathrm{L}^{-1}\right)$ & $3.4 \times 10^{-7}$ \\
\hline Quantitation limit $\left(\mathrm{mol} \mathrm{L}^{-1}\right)$ & $3.7 \times 10^{-6}$ \\
\hline
\end{tabular}

${ }^{\text {a }}$ Concentration level of $5 \times 10^{-5} \mathrm{~mol} \mathrm{~L}^{-1}$

${ }^{\mathrm{b}}$ Average on a concentration level of $5 \times 10^{-5} \mathrm{~mol} \mathrm{~L}^{-1}$

Applying different $\mathrm{pH}$ hydrolysis to pravastatin, its degradation products maintain the same UV-spectrum of the parent drug $(239 \mathrm{~nm})$, evidencing that the chromophore structure remains unaltered, which permits us conclude that only the ester moiety could be affected after the hydrolysis processes (insert in Figure 3). Our results obtained in the acid hydrolysis are not in agreement with a previous report, in which only one degradation product was obtained after the pravastatin hydrolysis at a short retention time, lower than pravastatin. Such study deals with a HPLC method develop for the determination of pravastatin in tablets and the hydrolysis carried out corresponds to a forced degradation or stress testing included in the selectivity probes of the HPLC method, and the corresponding chromatograms were followed only in short times $(7 \mathrm{~min} \text {. })^{12}$. As can be seen in Figure 3B, in our stability study, all the hydrolytic products in acid medium exhibited retention times higher than pravastatin, which indicates that the generated products are more lipophyllic than the parent drug and can be due to a successive esterifications and lactonization of pravastatin rather than the loss of the ester group. The full-scan MS/MS mass spectra of each peak in positive mode indicate that the most abundant product ion is found at $\mathrm{m} / \mathrm{z} 269$ for all peaks, and corresponds to a second fragmentation product as has been reported previously ${ }^{17-19,27}$. By using HPLC-MS/MS we have assigned the main degradation product (peak 2) as the pravastatin lactone form $\left(\mathrm{M}+\mathrm{H}^{+}=407\right.$; $\mathrm{M}$ $\left.\mathrm{C}_{5} \mathrm{H}_{10} \mathrm{O}_{2}=287 ; \mathrm{M}_{-} \mathrm{C}_{5} \mathrm{H}_{10} \mathrm{O}_{2}-\mathrm{H}_{2} \mathrm{O}=287\right)^{18}$, but due to the similar fragmentation pattern, the other peaks could not be assigned.

In alkaline medium only one hydrolysis product was generated with a retention time of $1.9 \mathrm{~min}$ (Figure 3C). This product was isolated by preparative TLC and as is expected, identified as the 8-hydroxy derivative (loss of 2methylbutanoic acid moiety) by ${ }^{1} \mathrm{H}-\mathrm{NMR}$ (CH-8 at $4.2 \mathrm{ppm}, 8-\mathrm{OH}$ at $\left.4.7 \mathrm{ppm}\right)$ and ${ }^{13} \mathrm{C}$-NMR (loss of 12-carbonyl signal at $185 \mathrm{ppm}$ ).

The time-course of products generated in both alkaline and acid hydrolysis are shown in Figure 4. As can be seen, the generation of products is dependent of the media tested. Thus in alkaline medium, the only one degradation product appears linearly as the pravastatin concentration decreases and is detectable after $50 \mathrm{hrs}$ of alkaline hydrolysis. Different behaviour is observed in acidic medium, in which the product 2 is quickly generated during the first minutes of hydrolysis and then 4 new products are generated. Also, a dissimilar behaviour of pravastatin decay is observed in both media. 

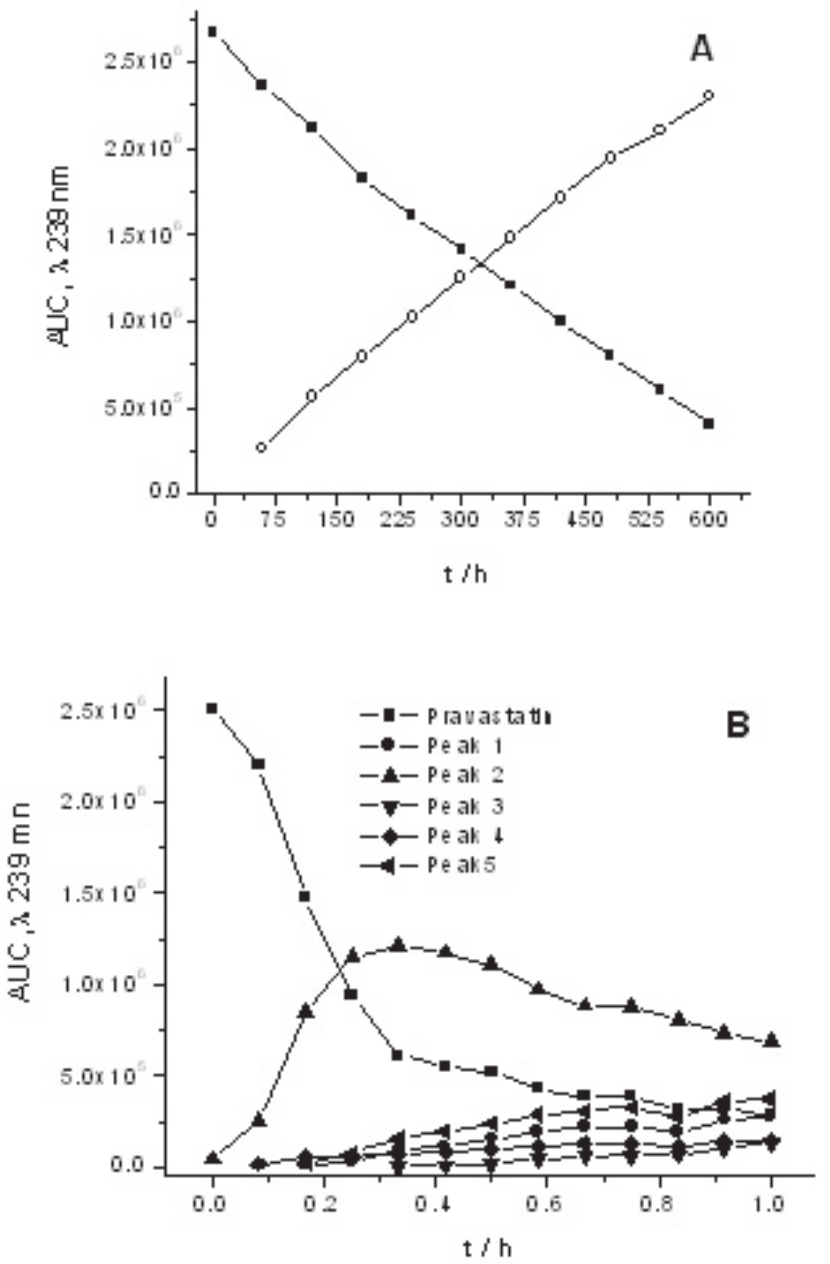

Figure 4. Decay evolution of $1 \times 10^{-4} \mathrm{~mol} \mathrm{~L}^{-1}$ pravastatin solution and appearance of it degradation products at $80^{\circ} \mathrm{C}$. (A) $\mathrm{pH} 12$, (B) $\mathrm{pH} 3$.

In order to determine the pravastatin stability at different $\mathrm{pHs}$ and temperatures, the developed analytical method was successfully applied. First of all, experiments under constant oxygen bubbling for $3 \mathrm{hrs}$. at different $\mathrm{pHs}$ $(3,7,10)$ were carried out, obtaining that pravastatin was not oxidized in such experimental conditions. Therefore, a nitrogenous atmosphere was not necessary to perform the degradation trials.

For the purpose of testing the kinetic order of the hydrolytic degradation, experiments at both different initial concentration and $\mathrm{pH}$ were performed. As can be seen from Figure 5, the ln $\mathrm{c} v s$ t plots were linear $(\mathrm{r}>0.9991)$ and the changes in the initial concentration of pravastatin did not affect the slopes of the decay curves. Furthermore, all the curves were parallel and their slopes were not statistically different applying F-test (variance proportion) and the $t$-Student test $(P=0.05, \mathrm{n}=7)$. In consequence, a pseudo-first order kinetic for the hydrolytic degradation of pravastatin can be assumed ${ }^{28}$.

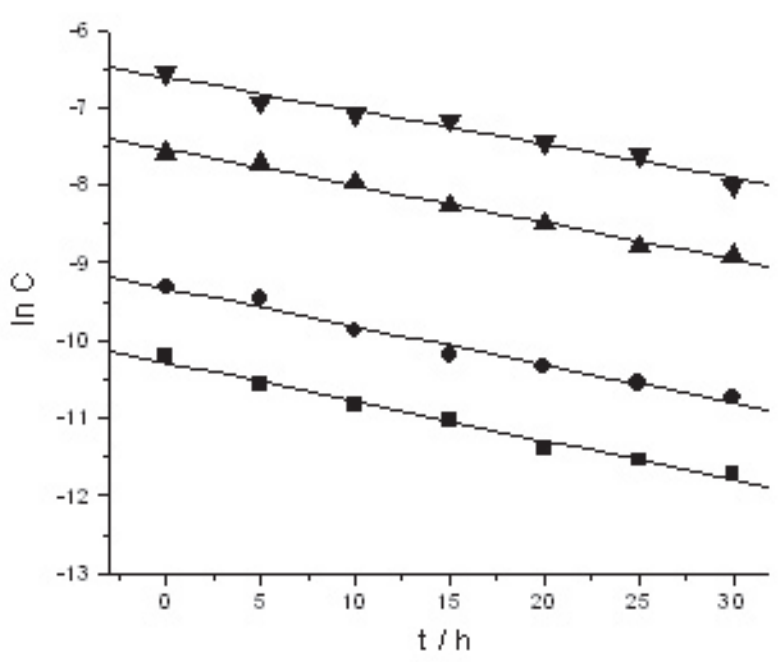

Figure 5. $\mathrm{Ln} \mathrm{C}$ vs t plots of pravastatin hydrolysis at $\mathrm{pH} 3,80^{\circ} \mathrm{C}\left(\boldsymbol{\nabla} 1 \times 10^{-3}\right.$ $\left.\mathrm{mol} \mathrm{L}-1 ; \boldsymbol{\Delta} \times 10^{-4} \mathrm{~mol} \mathrm{~L}^{-1} ; \bullet 1 \times 10^{-4} \mathrm{~mol} \mathrm{~L}^{-1} ; \square \times 10^{-5} \mathrm{~mol} \mathrm{~L}^{-1}\right)$

Degradation of pravastatin is dramatically influenced on both $\mathrm{pH}$ and temperature. As can be appreciated in Figure 6 , at $80^{\circ} \mathrm{C}$ of temperature, $k$ values diminish 11,74 and 5 folds between $\mathrm{pH} 3-9$ and then increases 38 folds between $\mathrm{pH}$ 9-12. In Table 2 constants values $(k)$ for the hydrolytic degradation of pravastatin at different temperatures are summarized. The stability of pravastatin increases concomitantly with the increasing of $\mathrm{pH}$ and this behavior is summarized in Figure 7, in which the $\mathrm{pH}$-rate hydrolysis profile for the pravastatin at $80^{\circ} \mathrm{C}$ is presented. As can be seen, $k$ values below pH 5 are relatively small and constant compared with $\mathrm{pH} 3$.

Table 2. Constants values $(k)$ for the hydrolytic degradation of pravastatin at different temperatures.

\begin{tabular}{|c|c|c|c|}
\hline \multirow{2}{*}{$\mathbf{p H}$} & \multicolumn{3}{|c|}{ Degradation constant $\left(\boldsymbol{k}, \mathbf{~ m i n}^{-1}\right) *$} \\
\cline { 2 - 4 } & $\mathbf{4 0}^{\mathbf{o}} \mathbf{C}$ & $\mathbf{6 0}^{\mathbf{o}} \mathbf{C}$ & $\mathbf{8 0}^{\mathbf{0}} \mathbf{C}$ \\
\hline $\mathbf{3}$ & $5.13 \times 10^{-3} \pm 6.94 \times 10^{-4}$ & $3.62 \times 10^{-2} \pm 1.90 \times 10^{-3}$ & $4.76 \times 10^{-2} \pm 3.20 \times 10^{-3}$ \\
\hline $\mathbf{5}$ & $9.76 \times 10^{-5} \pm 2.99 \times 10^{-6}$ & $5.10 \times 10^{-4} \pm 7.15 \times 10^{-5}$ & $4.21 \times 10^{-3} \pm 4.99 \times 10^{-4}$ \\
\hline $\mathbf{7}$ & $4.16 \times 10^{-6} \pm 2.75 \times 10^{-6}$ & $1.04 \times 10^{-5} \pm 1.43 \times 10^{-6}$ & $5.69 \times 10^{-5} \pm 9.04 \times 10^{-6}$ \\
\hline $\mathbf{9}$ & No determined & $2.41 \times 10^{-6} \pm 3.87 \times 10^{-7}$ & $1.11 \times 10^{-5} \pm 1.62 \times 10^{-6}$ \\
\hline $\mathbf{1 2}$ & $3.18 \times 10^{-5} \pm 9.74 \times 10^{-6}$ & $6.99 \times 10^{-5} \pm 7.98 \times 10^{-6}$ & $4.19 \times 10^{-4} \pm 3.83 \times 10^{-5}$ \\
\hline
\end{tabular}

$* k$ represents the average of four concentrations, $(\mathrm{p}<0.05)$

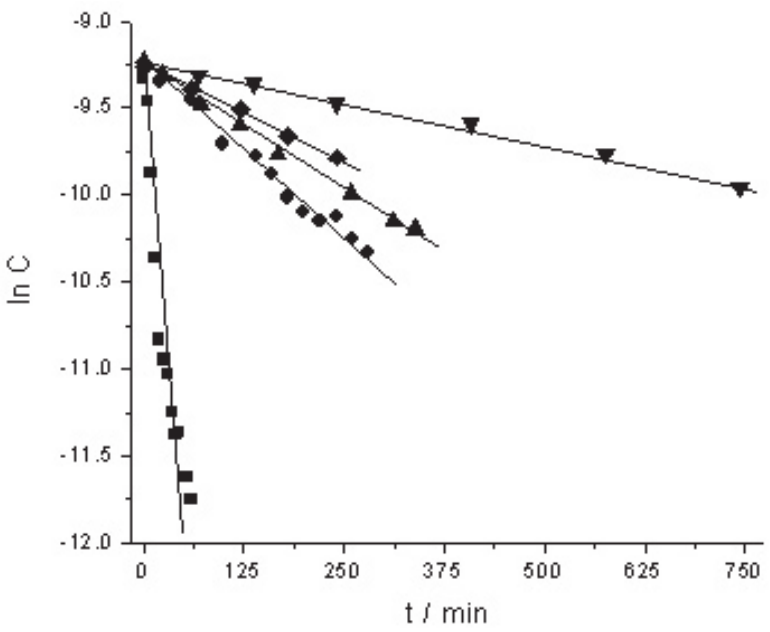

Figure 6. Effect of $\mathrm{pH}$ on $5.5 \times 10^{-5} \mathrm{~mol} \mathrm{~L}^{-1}$ pravastatin concentration at $80^{\circ} \mathrm{C}(\bullet \mathrm{pH} 3, \bullet \mathrm{pH} 5, \boldsymbol{\Delta} \mathrm{pH} 7, \boldsymbol{\nabla} \mathrm{pH} 9, \bullet \mathrm{pH} 12)$. 


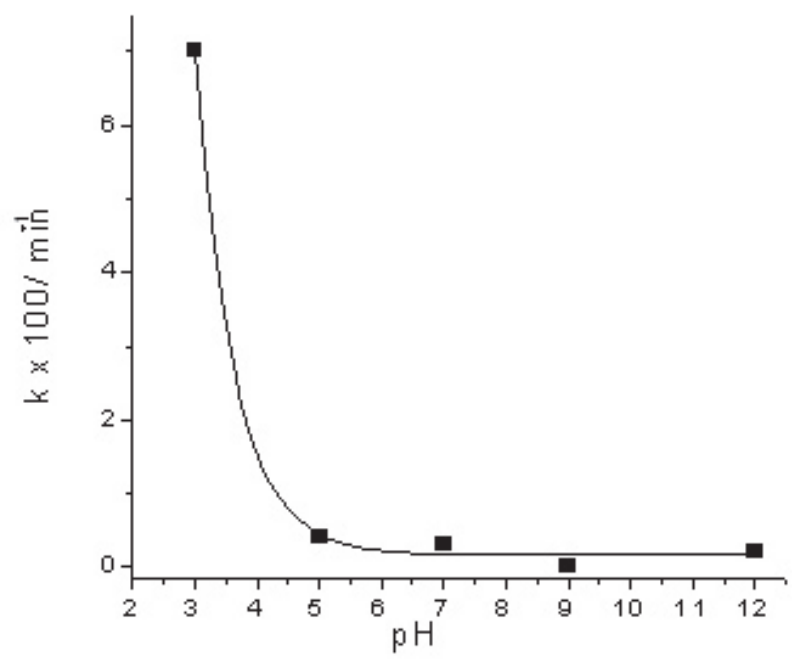

Figure 7. $\mathrm{pH}$-rate hydrolysis profile of pravastatin at $80^{\circ} \mathrm{C}$

Similar effects were obtained when pravastatin is exposed at different temperatures; $k$ values increases 4.1 and 2.3 folds parallel with the increase of temperature from $40^{\circ} \mathrm{C}$ to $80^{\circ} \mathrm{C}$ at $\mathrm{pH} 3$ (Figure 8 ). The calculated activation energy at $\mathrm{pH} 6\left(60^{\circ} \mathrm{C}\right)$ was $19.9 \mathrm{Kcal} / \mathrm{mol}$, a value which is consistent with the break of ester or lactone moieties ${ }^{28}$. Furthermore, the enthalpy had a value of $19.2 \mathrm{Kcal} / \mathrm{mol}$ and the free energy had a value of $-25.5 \mathrm{Kcal} / \mathrm{mol}$. The value of $\Delta \mathrm{G}<0$ implies that the hydrolysis under these experimental conditions was spontaneous.

In Table 3, both kinetic parameters at $80^{\circ} \mathrm{C}$ and the extrapolated ones at $25^{\circ} \mathrm{C}$ are summarized. From the extrapolated data at $25^{\circ} \mathrm{C}$, it can be seen that at $\mathrm{pH} 3$ and $\mathrm{pH} 5$, a $10 \%$ decrease of the initial concentration decay within $5 \mathrm{~min}$. and 1 hour, respectively. In contrast, at $\mathrm{pH} 7$ pravastatin was about 70 and 800 fold more stable than at $\mathrm{pH} 5$ and $\mathrm{pH} 3$, respectively.

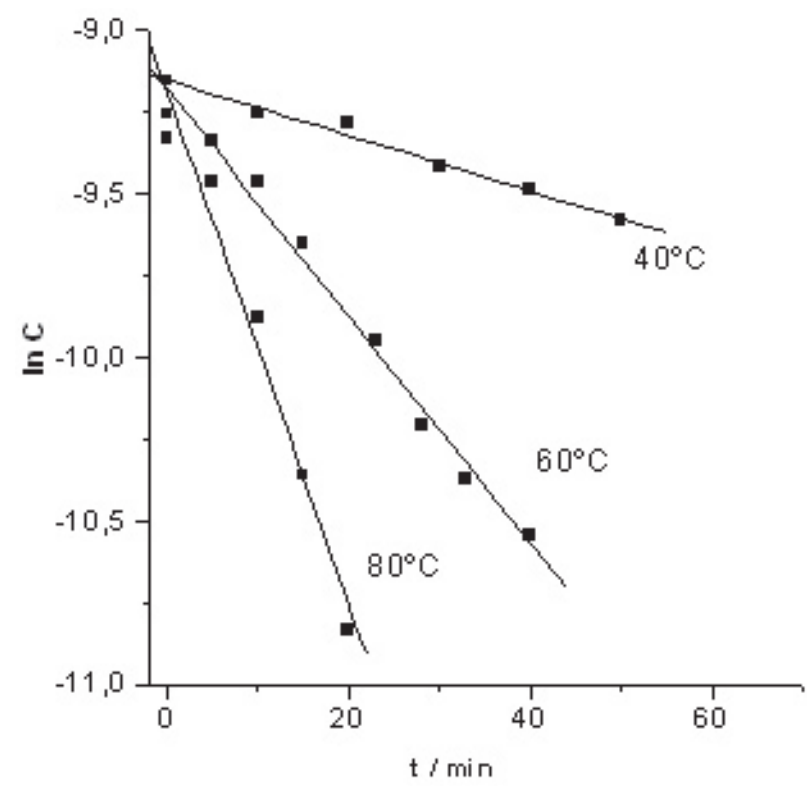

Figure 8. Effect of temperature on $1 \times 10^{-4} \mathrm{~mol} \mathrm{~L}^{-1}$ pravastatin concentration at $\mathrm{pH} 3$
Table 3. Kinetic parameters at $80^{\circ} \mathrm{C}$ and extrapolated at $25^{\circ} \mathrm{C}$ for the hydrolytic degradation of pravastatin.

\begin{tabular}{|c|c|c|c|c|c|}
\hline \multirow{2}{*}{$\mathbf{p H}$} & \multicolumn{2}{|c|}{$\mathbf{T}=\mathbf{8 0}^{\mathbf{0}} \mathbf{C}$} & \multicolumn{3}{c|}{$\mathbf{T}=\mathbf{2 5}^{\mathbf{0}} \mathbf{C}$} \\
\cline { 2 - 6 } & $\left.\boldsymbol{k} \mathbf{( m i n}^{-1}\right)$ & $\mathbf{t}_{1 / 2} \mathbf{( h )}$ & $\left.\boldsymbol{k} \mathbf{m i n}^{-1}\right)$ & $\mathbf{t}_{\mathbf{1} / \mathbf{2}} \mathbf{( h )}$ & $\mathbf{t}_{\mathbf{9 0}} \mathbf{( h )}$ \\
\hline $\mathbf{3}$ & $4.76 \times 10^{-2}$ & 0.24 & $2.05 \times 10^{-2}$ & 0.56 & 0.09 \\
\hline $\mathbf{5}$ & $4.21 \times 10^{-3}$ & 2.74 & $1.81 \times 10^{-3}$ & 6.38 & 0.97 \\
\hline $\mathbf{7}$ & $5.69 \times 10^{-5}$ & 203 & $2.45 \times 10^{-5}$ & 471 & 71.43 \\
\hline $\mathbf{9}$ & $1.11 \times 10^{-5}$ & 1040 & $4.78 \times 10^{-6}$ & 2416 & 366 \\
\hline $\mathbf{1 2}$ & $4.19 \times 10^{-4}$ & 28 & $1.81 \times 10^{-4}$ & 63.81 & 9.67 \\
\hline
\end{tabular}

\section{ACKNOWLEDGEMENTS}

Authors are very grateful with the support of FONDECYT Grant $\mathrm{N}^{\circ}$ 1030737 .

\section{REFERENCES}

1. R.S. Blumenthal, Am. Heart J., 139, 577, (2000)

2. Clarke's Analysis of Drugs and Poisons 2004. Consulting Editors: A.C Moffat, M. D. Osselton, B. Widdop. Managing Editor: L.Y. Galichet. Pharmaceutical Press, 2004.

3. ICH, Stability testing of New Drugs Substances and Products: Proceeding of the International Conferences on Harmonization, IFPMA, Geneva, 2000

4. B. Kommanaboyina, C.T. Rhodes, Drug. Dev. Ind. Pharm. 25, 857, (1999)

5. K.C.Waterman, C.R. Adami, K.M. Alsante, A.S. Antipas, D.R. Arenson, R. Carrier, J. Hong, M.S. Landis, F. Lombardo, J.C. Shah, E. Shalaev, S.W. Smith, H. Wang, Pharm. Dev. Technol. 7, 113, (2002)

6. N.Y. Coskun, S. Aycan, S. Sungur, Pharmazie 52, 485, (1997)

7. K. Kırcalı, M. Tunçel, H.Y. Aboul-Enein, Farmaco 59, 241, (2004)

8. S. Bauer, J. Mwinyi, A. Stoeckle, T. Gerloff, I. Roots, J. Chromatogr. B 818, 257, (2005)

9. D.-J. Yang, L. Sun Hwang, J. Chromatogr. A 1119, 277, (2006)

10. R.Grahek, D. Milivojevic, A. Bastarda, M. Kracun, J. Chromatogr. A 918 , 319, (2001)

11. K. Otter, C. Mignat, J. Chromatog. B 708, 235, (1998)

12. A. Önal, O. Sagirli, Chromatographia 64, 157, (2006)

13. S.Bauer, J. Mwinyi, A., Stoeckle, T. Gerloff, I. Roots, J. Chromatogr. B 818, 257, (2005)

14. Z. Zhu, L. Neirinck, J. Chromatogr. B 783, 133, (2003)

15. R. Nirogi, K. Mudigonda, V. Kandikere, J. Pharm. Biomed. Anal. 44, 379, (2007)

16. K. Kawabata, N. Matsushima, K. Sasahara, Biomed. Chromatogr. 12, 271, (1998)

17. X.S. Miao, C.D. Metcalfe, J. Chromatogr. A 998, 133, (2003)

18. D. Mulvana, M. Jemal, S. Coates Pulver, J. Pharm. Biomed. Anal. 23, 851, (2000)

19. K. Kawabata, N. Samata, Y. Urasaki, J. Chromatogr. B 816, 73, (2005)

20. H.Y. Pan, A.R. DeVault, D. Wang-Iverson, E. Ivashkive, B.N. Swanson, A.A. Sugerman, J. Clin. Pharmacol. 30, 1128, (1990)

21. A. Kocijan, R. Grahek, A. Bastarda, L. Zupançiç Kralj, J. Chromatogr. B 822, 311, (2005)

22. S. Ertürk, A. Önal, S. Muge Çetin, J. Chromatogr. B 793, 193, (2003)

23. M.K. Pasha, S. Muzeeb, S.J. Basha, D. Shashikumar, R. Mullangi, N.R. Srinivas, Biomed. Chromatogr. 20, 282, (2006)

24. USP 27-NF 22. United States Pharmacopoeial Convention, Inc., Rockville M.D. USA, 2004.

25. O.A. Quattrochi, S.A. De Andrizzi, R.F. Laba, Introducción a la HPLC, aplicación y práctica, Artes Gráficas Farro SA, Buenos Aires, 1992.

26. AOAC Peer Verified Methods Program, Manual on Policies and Procedures, AOAC International, Arlington, VA, 1993.

27. A. Kocijan, R. Graheka, L. Zupančič-Kralj, Acta Chim. Slov. 53, 464, (2006)

28. K.A. Connors, C.L. Amidon, V.J. Stella, Chemical Stability of Pharmaceuticals: a Handbook for Pharmacists, Wiley-Interscience, New York., NY, 1986. 